\title{
Modeling and Simulation on Flat Section of Large Ship Welding Workshop
}

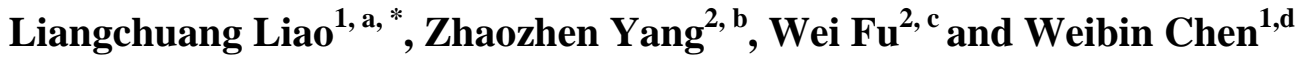 \\ ${ }^{1}$ No.716 Research Institute of China Shipbuilding Industry Corporation, Lianyungang 222000, China \\ ${ }^{2}$ School of Harbin Engineering University, Harbin 150001, China \\ allc841017@126.com, ${ }^{b} 1781772958 @ q q . c o m,{ }^{c}$ fuwei@hrbeu.edu.cn, jari_chris@163.com
}

Keywords: flat section; welding workshop; software Plant Simulation; discrete system simulation

\begin{abstract}
To study the flat section welding intelligence workshop, the system modeling is an essential step. A digital transformation of workshop section process was introduced.The simulation model is set up by using of the software Plant Simulation. Simulate workshop production process by simulation and various elements that influent the production to further improve the authenticity of the simulation system.
\end{abstract}

\section{Introduction}

Nowdays,shipbuilding, characterized by section construction,mainly adopts welding process ${ }^{[1]}$. It is a huge and complicated system engineering, and many factors can affect the production in the process of building. It is difficult to accurately describe with a simple mathematical model. Compared with the mathematical deduction, using simulation technology to analyse the production process will not consume resources. It is able to simulate production system and its influence factors.By analyzing the simulation results, the influence factors can be adjusted or optimized to improve the ship construction efficiency.

\section{Flat Section Production Line and Production Data Acquisition.}

The workshop adopts the assembly line mode to organize production, which is the mode of fixed work place and mobile products. FCB jigsaw welding equipment, FWG automatic angle welding machine, multi-function cabin welding robot system, automatic roller conveyor line and other automatic equipments are used in the flat section assembly line.The concrete process of flat section process is showen as followed.

\subsection{Panel Welding}

The polish of welding seam is done manually, and the position welding is done after compaction. The welding process plate is sealed at both ends of the seam and the steel plate is transported to FCB jigsaw welding station by automatic transport line.

\subsection{Longitudinal Bone Welding}

On the jigsaw, the $\mathrm{T}$ section is carried by electromagnetic lifting to the top of the collage, then aligned. Position welding is applied manually, and then longitudinal bone welding is carried by FWG longitudinal bone angle welding machine.

\subsection{Rib Plate Welding}

Datum line is made artificially on rib plate[2]. Weld rings on the plate, then hang it to the position above the floor plate, install rope, pull it in to line position. The workers correct the position and make tack welding. 


\subsection{Workstation Configuration}

Through the data acquisition of the production line of the section welding workshop in a shipyard, the data source is provided for the system modeling. Flat section production line has 10 stations, and they are flat plate assembly station, flat plate welding station, repair station, longitudinal assembly station, longitudinal welding station, buffer station, rib plate assembly station, rib plate welding station, pre-outfitting station,examinization station.

\subsection{Statistics of Working Time}

Through the field investigation of a section workshop, the time and processing amount of each workshop production process are collected, and the actual processing capacity of the station is calculated.

Table 1 Time of Every Workstation

\begin{tabular}{|c|c|c|c|c|c|}
\hline Numble & Name & Time/min & Number & Name & Time/min \\
\hline 1 & panel assembly station & 150 & 6 & buffer station & 40 \\
\hline 2 & panel welding station & 144 & 7 & $\begin{array}{c}\text { rib plate assembly } \\
\text { station }\end{array}$ & 300 \\
\hline 4 & repair station & 35 & 8 & $\begin{array}{c}\text { rib plate welding } \\
\text { station }\end{array}$ & 300 \\
\hline 5 & $\begin{array}{c}\text { longitudinal assembly } \\
\text { station }\end{array}$ & 180 & 9 & pre-outfitting station & 300 \\
\hline
\end{tabular}

\section{Modeling and Simulation and Bottleneck Analysis of Flat Section Production Line}

\subsection{Flat Section Modeling}

Flat section production line has 10 stations[3], and the panel assembly station, longitudinal assembly station, rib plate assembly station, pre-outfitting station belong to assembly station. Take 'Assembly'to simulate them, and the rest are process station which are simulated by 'Single-proc'.

The material loading of steel plate, longitudinal bone, rib plate, fitting-out piece is simulated by Source/Source1/Source2/Source3.Steel plate is simulated by Container. Longitudinal bone, rib plate and fitting-out piece are simulated by Entity1、Entity2、 Entity3.

\subsection{Simulation of Workshop Production Plan}

Shipyard usually makes production plan by Excel.In order to reduce the workload of simulation input data, lead shipyard production plan in the Excel spreadsheet data directly into the Plant Simulation to realize the Excel and Plant Simulation data link.Before the production plan being issued, take the preliminary inspection on production plan to judge whether it is reasonable. Call the Readexcelfile interface function and run the command to read the Excel data into Plant Simulation.

\subsection{Simulation of Scheduling and Failure Rate Factor}

Make scheduling plan by shiftcalendar and schedule the production line running in the scheduled time. The scheduling plan is as follows, weekly working hours from Monday to Friday, two shifts a day, the early hours of work from 6:00 to14:00, late working time from 14:00 to 22:00.Among them, 9:00-9:15, 18:00-18:30 are break time, production line stops running during this time.

Each station on the production line has breakdown possibility because of machine failure or human error, leading to station stop runing normally. Therefore, the factor of the failure rate needs to take into consideration .In the singleproc object table, the equipment can be set by availability. The availability refers to equipment availability,and MTTR represents mean repair time of the equipment. In this paper, the availability of equipment for all stations is 95\%, and the MTTR is 3600 seconds on average. 


\subsection{System Parameter Setting}

For the system simulation model established in section 4, the global variable is set, and the global variables in the model are defined as shown in the table below.

Table 2 Global Variable Definition in Model Layer

\begin{tabular}{|c|c|c|c|}
\hline Variable Name & $\begin{array}{c}\text { Initial } \\
\text { Value }\end{array}$ & $\begin{array}{c}\text { Data } \\
\text { Type }\end{array}$ & Meaning \\
\hline Availability & $95 \%$ & Real & Availability of Equipment \\
\hline MTTR & 3600 s & Real & $\begin{array}{c}\text { Meaning Time of } \\
\text { Repariation (sec) }\end{array}$ \\
\hline Sigma & 10 & Real & $\begin{array}{c}\text { Standard Deviation of } \\
\text { Processing Time } \\
\text { Fluctuation(sec) }\end{array}$ \\
\hline
\end{tabular}

Processing time of each station is the most important parameter of the simulation model and it is getted from investagation on-the-pot.

\subsection{Equipment Running Rate and Bottleneck Station Analysis}

The operating time is 30:00:00:00, i.e. 30 days.Run the simulation model[4], and the monthly output of 173 flat sections is obtained, and the simulation runs is shown in the following figure.

Table 3 Equipment Running Rate Statics

\begin{tabular}{|c|c|c|c|c|}
\hline Work Station & $\begin{array}{c}\text { Running } \\
\text { Rate }\end{array}$ & $\begin{array}{c}\text { Blocking } \\
\text { Rate }\end{array}$ & $\begin{array}{c}\text { Waiting } \\
\text { Rate }\end{array}$ & $\begin{array}{c}\text { Falier } \\
\text { Rate }\end{array}$ \\
\hline 1 & $62 \%$ & $34 \%$ & $0 \%$ & $4 \%$ \\
\hline 2 & $60 \%$ & $35 \%$ & $2 \%$ & $3 \%$ \\
\hline 3 & $15 \%$ & $77 \%$ & $3 \%$ & $5 \%$ \\
\hline 4 & $75 \%$ & $16 \%$ & $2 \%$ & $7 \%$ \\
\hline 5 & $42 \%$ & $30 \%$ & $23 \%$ & $5 \%$ \\
\hline 6 & $16 \%$ & $23 \%$ & $57 \%$ & $4 \%$ \\
\hline 7 & $85 \%$ & $10 \%$ & $0 \%$ & $5 \%$ \\
\hline 8 & $85 \%$ & $38 \%$ & $4 \%$ & $6 \%$ \\
\hline 9 & $86 \%$ & $2 \%$ & $8 \%$ & $4 \%$ \\
\hline 10 & $33 \%$ & $0 \%$ & $63 \%$ & $4 \%$ \\
\hline
\end{tabular}

It can be seen that the equipment running rate of each station is not balanced in stable production[5,6]. The operation rate of rib plate welding station and pre-outfitting station is higher than other stations.The blocking rate of the station before the pre-outfitting station is generall higher, and after the pre-outfittin station the waiting rate is pretty high, indicating that pre-outfitting station is the "bottleneck" restriction for the whole production line.

\section{Conclusions}

On the analysis of the flat section digitization transform of a workshop production line, discrete system simulation model flat section production line is established on the basis of using the simulation software Plant Simulation. Analyze the equipment work situation and the bottleneck station, assessment flat section production ability. The results showed that the pre-outfitting station is the "bottleneck" station. 


\section{Acknowledgments}

This work was financially supported by digital workshop terminology and general technical requirements for standard research and test verification[2015]415, which is the part of the project: Intelligent manufacturing special project in 2015. Corresponding author: Wei Fu. E-mail: fuwei@hrbeu.edu.cn.

\section{References}

[1] Kumar R R, Kumar A, Kumar S. Evaluation of processes parameter and mechanical properties in friction stir welded steels[J]. International Journal of Mechanical Engineering and Technology, 2017, 8(2): 183-193.

[2] Zhang S, Norato J A. Optimal Design of Panel Reinforcements with Ribs Made of Plates[J]. Journal of Mechanical Design, Transactions of the ASME, 2017, 139(8).

[3] CHEN C I.A. bottleneck-based heuristic for minimizing make span in a flexible flow line with unrelated parallel machines [J]. Computers \& Operations Research, 2009, 36(11):3073-3081P

[4] OMAR M K, TEO S C, YASOTHEI S. Mixed integer programming formulation for hybrid flow shop scheduling problem[C]. Proceedings of the 2010 IEEE Conference on IEEM. Washington. D.C,USA: IEEE, 2010:385-389P.

[5]Lee J K, Lee K J, Park H K. Developing Scheduling Systems for Daewoo Shipbuilding: DAS Project[J]. European Journal of Operational Research, 1997, 97(2):380-395P.

[6]LAW AM. Simulation of manufacturing system[C]. In Proceedings of the 1997 Winter Simulation Conference, 1997:86-89P. 